\title{
SINGLE PASS BEAM POSITION MONITOR OF NEWSUBARU
}

\author{
Y. Shoji, A. Ando, S. Hashimoto, LASTI, Himeji Institute of Technology, NewSUBARU/SPring-8, \\ Kamigori, Hyogo 678-1205 Japan \\ T. Ohshima, Y. Kawashima, SPring-8, Mikazuki-cho, Hyogo 679-5198, Japan
}

\begin{abstract}
A single pass beam position monitoring system was installed at NewSUBARU. The system was so simple that it was developed and installed in a week. Bipolar bunch signals extracted through button electrodes were recorded in real time using digital oscilloscopes. The beam positions and intensity were determined from peak-topeak signal height. The system worked as a powerful tool during the comissionning.
\end{abstract}

\section{INTRODUCTION}

The synchrotron radiation (SR) facility NewSUBARU [1] is a light source in the SPring-8 site which uses the 1.0 $\mathrm{GeV}$ linac as an injector. LASTI (Laboratory of Advanced Science and Technology for Industry) of Himeji Institute of Technology is in charge of the construction and operation collaborating with SPring-8. Hyogo prefecture supports the financial costs of both construction and operation of the facility.

The beam commissioning started in September 1998. At that time the single pass BPM system was constructed and installed in a week. The existing BPMs and the signal cables for the c.o.d. BPM system were used for the new single pass BPM system. The existing signal route for the single pass BPM was not used, because there was a BPF in it and the system would be less sensitive to a weak signal. The purpose of the new system was to monitor the trajectory of the injection beam and help tuning of injection parameters at the initial stage of the commissioning. The requirements for the system were the followings,

(1) The accuracy of beam position was $1 \mathrm{~mm}$.

(2) It was capable of measuring very large displacement of beam.

(3) It gave information of a beam intensity in order to know where the beam loss took place.

(4) It could detect very weak beam.

In the following sections we report on the signal processing for the single pass measurements and some results of the position measurements of the initial several turns in the storage ring.

\section{SIGNAL PROCESSING}

The ring has 18 BPMs, which are separated into two groups, 9 BPMs in the eastern arc and the other 9 in the western arc. We constructed two sets of the system. Each system worked for each arc. The structure and signal processing scheme of a system is shown in Fig. 1.

A fast digitizing oscilloscope (Tektronix TDS684A or Hewlett Packard Infinium) was used as a detector of bunch signals. It had four channels with four 8-bit analogue-to-digital converter (ADC) with a maximum sampling rate of $5 \mathrm{Gs} / \mathrm{s}$. or $8 \mathrm{Gs} / \mathrm{s}$. and an analogue band width of $1 \mathrm{GHz}$ or $1.5 \mathrm{GHz}$. The signals from the four button electrodes of one BPM could be simultaneously recorded in the four channels by real-time sampling.

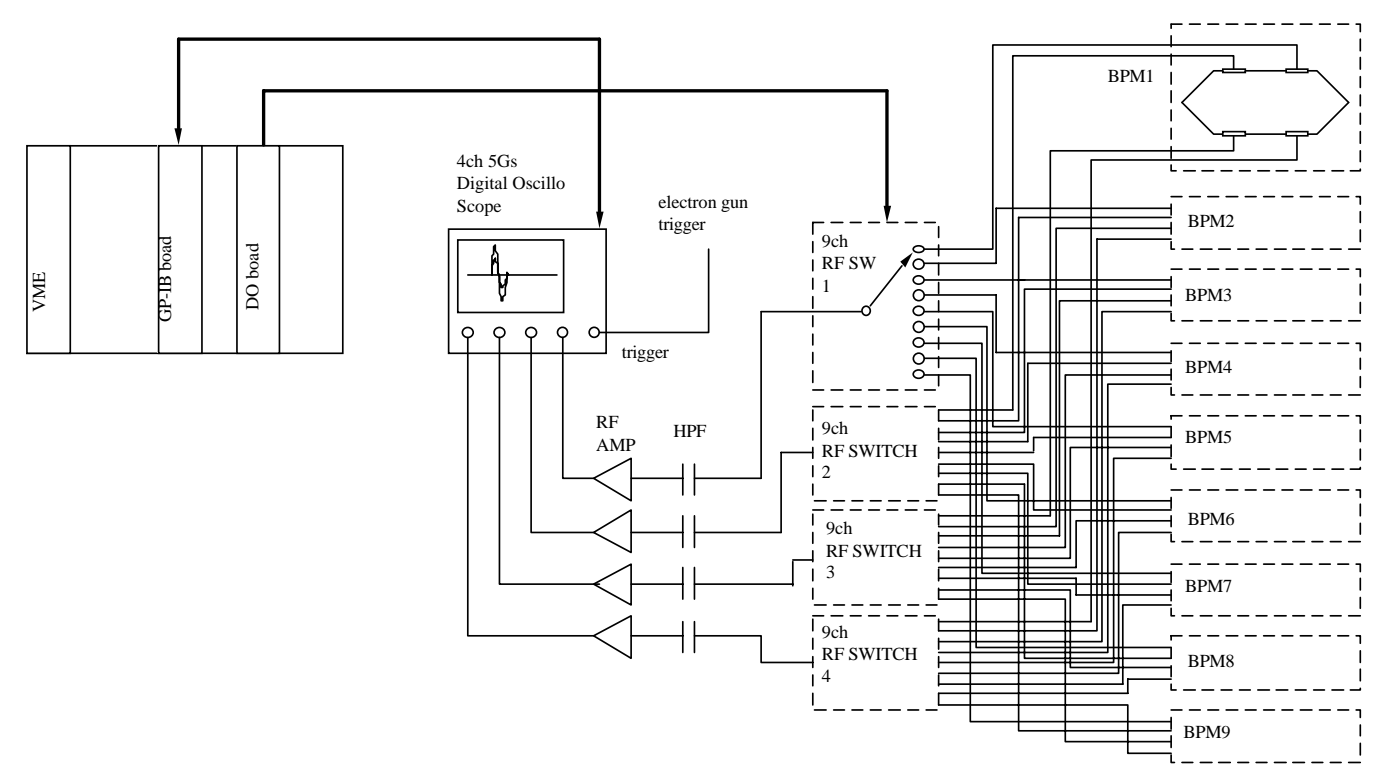

Figure 1: One unit (half) of the system 
The signal cable is a co-axial cable(SHUNER S 04272 B), which attenuation factor is $21 \mathrm{~dB} / 100 \mathrm{~m}$ at a frequency of $500 \mathrm{MHz}$. The cable lengths are $30 \mathrm{~m}, 38 \mathrm{~m}$ or $45 \mathrm{~m}$, however the lengths of four cables to the same BPM are the same within $1 \mathrm{~cm}$. RF switches were used to select BPM. The selected signal passed the HPF to reject the noise from pulse magnets. In order to keep a good signalto noise ratio, RF amplifier of $30 \mathrm{~dB}(10 \mathrm{MHz}-1 \mathrm{GHz})$ was inserted in the each signal path.

A pulsed beam of 1 ns width was injected in to a single RF bucket of the ring, where the beam contained 3 bunches in the linac RF bucket. A typical charge of the $1 \mathrm{~ns}$ pulse was $0.15 \mathrm{nC}$. Fig. 2 shows the observed pulse shape at the oscilloscope. The peak-to-peak voltage was calculated in the oscilloscope and was used to calculate positions in the control computer.

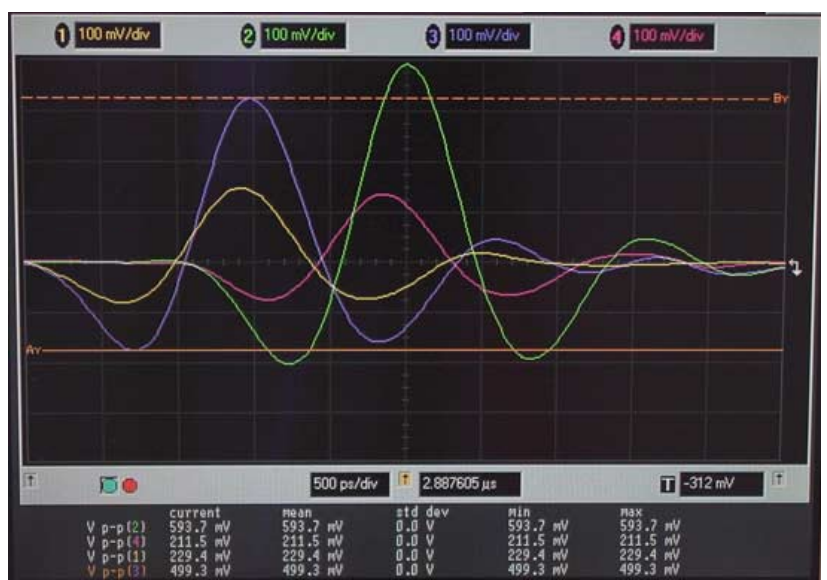

Figure 2: Shape of the detected signal.

The signal attenuation from BPM to the oscilloscope was calibrated by Lambertson's method [2] using $500 \mathrm{MHz}$ signal. This is a frequency of RF acceleration. The imbalance of 4 channels was $2 \%$ r.m.s. Later the beam intensity for each BPM was re-calibrated using the stored beam. We had underestimated the attenuation of the longer cables than the shorter cable by about $10 \%$. This was because we had used the fixed frequency signal (500MHz).

The system was controlled by the main control system. It worked according to the following sequence,

(1) Select one BPM for each unit of the system.

(2) Select a number of turn. The internal delay of the oscilloscope is automatically set to an appropriate value, calculated from a known delay for each BPM and the number of turn.

(3) Fires the electron gun and the oscilloscope triggers.

(4) Get peak-to-peak voltage of the signals from the oscilloscope.

(5) Apply correction of the attenuation.

(6) Calculate beam position and the intensity (output voltage corrected so that it is proportional to the beam intensity).

\section{CALCULATION}

The beam position and the intensity are calculated from the peak-to-peak signal heights of from electrodes. After the correction of the signal attenuation, beam positions (X and $\mathrm{Y}$ ) and the pulse intensity (Vave) are calculated using the following equations.

$$
\begin{aligned}
& \mathrm{U}=[(\mathrm{V} 1-\mathrm{V} 2) /(\mathrm{V} 1+\mathrm{V} 2)+(\mathrm{V} 4-\mathrm{V} 3) /(\mathrm{V} 4+\mathrm{V} 3)] / 2 \\
& \mathrm{~V}=[(\mathrm{V} 1-\mathrm{V} 4) /(\mathrm{V} 1+\mathrm{V} 4)+(\mathrm{V} 2-\mathrm{V} 3) /(\mathrm{V} 2+\mathrm{V} 3)] / 2 \\
& \mathrm{~S}=\mathrm{U} /\left(1-\mathrm{U}^{2}\right) \\
& \mathrm{T}=\mathrm{V} /\left(1-\mathrm{V}^{2}\right)
\end{aligned}
$$

$$
\begin{aligned}
X & =S\left(8.4437-4.7408 \mathrm{~T}^{2}\right)+\mathrm{S}^{3}\left(-1.1528+1.4278 \mathrm{~T}^{2}\right) \\
& +\mathrm{S}^{5}\left(0.1482-0.1940 \mathrm{~T}^{2}\right)+\mathrm{S}^{7}\left(-1.0312+1.3273 \mathrm{~T}^{2}\right) \times 10^{-2} \\
& +\mathrm{S}^{9}\left(3.8561-4.7513 \mathrm{~T}^{2}\right) \times 10^{-4}+\mathrm{S}^{11}\left(-7.29+8.45 \mathrm{~T}^{2}\right) \times 10^{-6} \\
& +\mathrm{S}^{13}\left(5.47-5.83 \mathrm{~T}^{2}\right) \times 10^{-8}
\end{aligned}
$$

$$
\begin{aligned}
\mathrm{Y}= & {\left[21.328+0.001932 \mathrm{~S}^{4}+3.78 \times 10^{-5} \mathrm{~S}^{6}+4.14 \times 10^{-8} \mathrm{~S}^{10}\right.} \\
& \left.-6.28 \mathrm{~S}^{2} /\left(1+\mathrm{S}^{2}\right)\right] \mathrm{T} \\
& +\left[8.109+0.0207 \mathrm{~S}^{4}-4.49 \times 10^{-4} \mathrm{~S}^{6}+7.6 \times 10^{-8} \mathrm{~S}^{10}\right. \\
& \left.-11 . \mathrm{S}^{2} /\left(1+\mathrm{S}^{2}\right)\right] \mathrm{T}^{3}
\end{aligned}
$$

$$
\begin{aligned}
& \text { Vave }=(\mathrm{V} 1+\mathrm{V} 2+\mathrm{V} 3+\mathrm{V} 4) / 4 \\
& \quad /\left[1+4.09 \times 10^{-3} \mathrm{X}^{2}-1.1 \times 10^{-5} \mathrm{X}^{4}+2.98 \times 10^{-9} \mathrm{X}^{6}\right] \\
& \quad /\left[1-3 \times 10^{-3} \mathrm{Y}^{2}\right]
\end{aligned}
$$

Here Vi represents the pulse height of the signal from the $\mathrm{i}$-th electrode. $\mathrm{X}$ and $\mathrm{Y}$ are horizontal and vertical beam position in $\mathrm{mm}$. Vave is a corrected pulse intensity so that it is proportional to the beam.

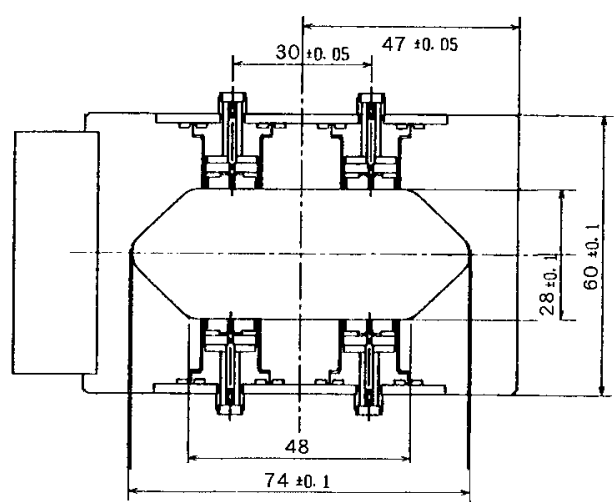

Figure 3: Cross section of the BPM.

The coefficients in the equations were determined from the results of two-dimensional field calculation. Fig.3 shows the cross section of BPM. The errors of fitting with the functions were negligibly small compared to the measurement error. They are less than $0.2 \mathrm{~mm}$ for $\mathrm{X}$ and $\mathrm{Y}$ and $0.5 \%$ for Vave in the large area of $25 \mathrm{~mm}<\mathrm{X}<25 \mathrm{~mm},-10 \mathrm{~mm}<\mathrm{Y}<10 \mathrm{~mm}$.

\section{MEASUREMENTS}

Fig. 4 is an example of data took in the early commissioning of NewSUBARU. The reproducibility of the beam position was roughly $1 \mathrm{~mm}$, which contains shot by shot fluctuation of the injected beam. When we needed more accuracy, we took an average of many shots. Even 
for a beam excursion of as large as $20 \mathrm{~mm}$, we could reproduce the position from the signal. However when $\mathrm{X}$ is more larger the calculated $\mathrm{X}$ is tend to be smaller than the real $\mathrm{X}$ because of the noise in a small signal.

It happened many times that the balance of $\mathrm{V} 1, \mathrm{~V} 2, \mathrm{~V} 3$ and V4 was unusual. In that case a beam loss happened near the BPM and we cannot use these signal data.

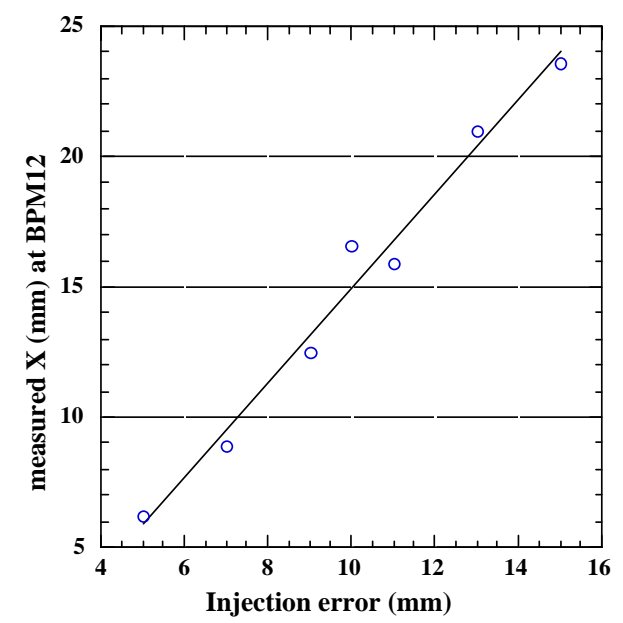

Figure 4: Results of monitoring beam position when the horizontal displacement is very large.

Fig. 5 shows an example of the change of pulse intensity along the beam passage. The plot shows that the $20 \%$ beam loss happened near BPM6 at the first turn and then near the injection point (BPM1) at the third turn. The main origin of the fluctuation of data came from the shot by shot fluctuation of the linac beam. When we needed more accurate measurement, we fixed the selection of BPM in the eastern arc and took measurements changing the selection in the western arc. Then we took a ratio of the intensity of the western arc to the eastern arc. This reduced the shot by shot fluctuation of the data on the western arc.

\section{SUMMARY}

The single-pass BPM system of NewSUBARU worked very well during its early commissioning period. The system was very simple and was easily constructed. It covers very wide area in the cross section of BPM. It also identified where the beam loss took place.

\section{ACKNOWLEDGEMENT}

We thank members of SPring-8 who joined the commissioning of NewSUBARU. We also thank members of SPring-8 linac group for their help in the hardware. We thank Dr. N. Kumagai, the head of SRring$8 \mathrm{SR}$, for a essential support to the project.

\section{REFERENCES}

[1] S. Hashimoto, et al., "PRESENT STATUS OF THE SYNCHROTRON RADIATION FACILITY NEWSUBARU", this proceedings.

[2] G. R. Lambertson, LBL, ALS, LSAP NOte-5, May 6,1987 .

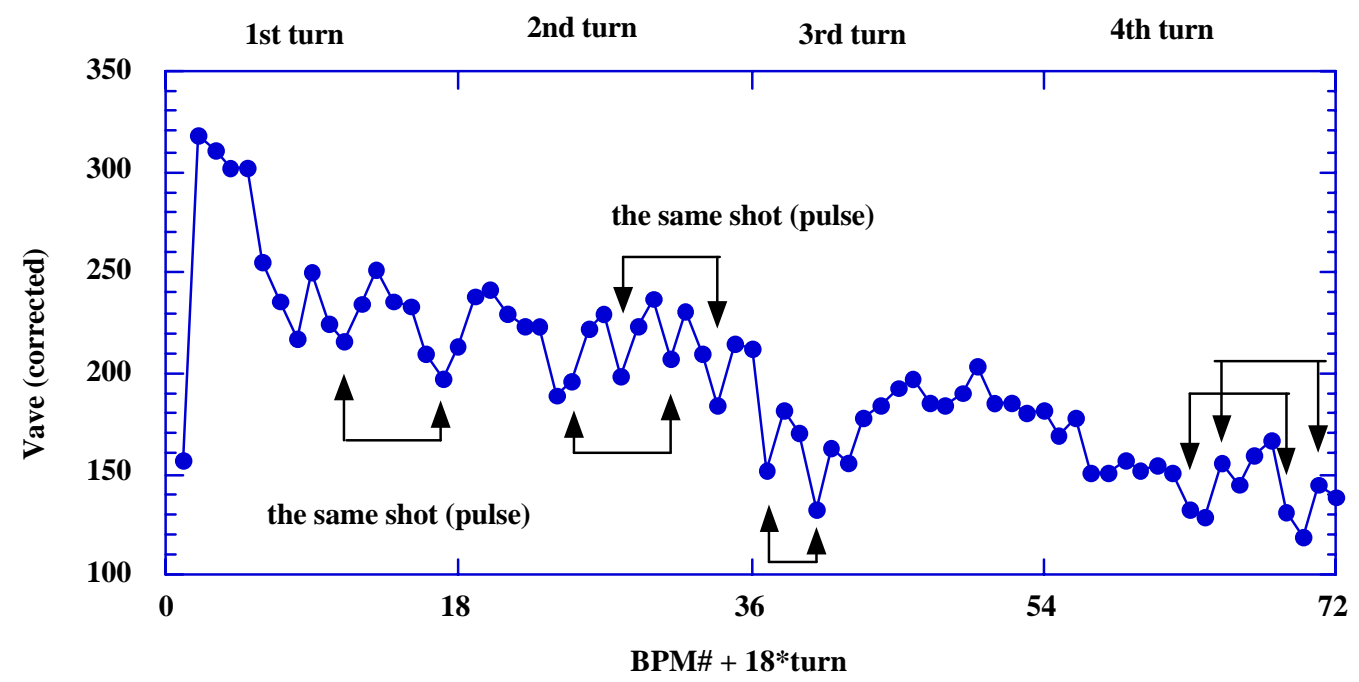

Figure 5: A change of the pulse intensity. 